\title{
INTERPRETATION OF INTERNET MEMES AND ADVERTISEMENTS THROUGH SEMIOTIC AND RECEPTION STUDIES
}

\author{
Akshay Razdan \\ Student \\ IIMC NER Campus
}

\begin{abstract}
The study focuses on gauging how the communication occurs when a viewer is exposed to a meme and advertisement. It attempts to understand the creation of meaning by deconstructing the visual and verbal components.

This study is an attempt to explain how the relation between images, text and meanings connect with each other to form social messages, political, universal emotions and entertain users. A further analysis is conducted to decipher the impression on the mind of the viewer, i.e. an attempt to 'understand his understanding 'of the subject. Thus, a combined analysis should evaluate the gaps and merits in the communication channel.

The viewer of an advertisement might access and use socio-cultural values, norms and presets of preloaded notions to interpret the message which deviates from direct logical meaning. Lack of familiarity and knowledge can hinder the communication process to a great extent as the viewer lacks the tools (assuming him/her a faculty of mind) to interpret the underlying message, i.e. only purported logical meaning cannot necessarily embark upon the viewer's impression. Hence, mind can exhibit confusion or face hindrance while interpreting the message.
\end{abstract}

Keywords - Internet memes, advertisements, semiotics, reception analysis, Semiotic Theory of Charles Sanders Pierce, Saussure, representamen, object, interpretant.

\section{INTRODUCTION}

The study on "Interpretation of Internet Memes And Advertisements through Semiotic and Reception Studies" focuses on gauging how the communication occurs when a viewer is exposed to a meme and advertisement. It attempts to understand the creation of meaning by deconstructing the visual and verbal components. This study is an attempt to explain how the relation between images, text and meanings connect with each other to form social messages, political, universal emotions and entertain users. A further analysis is conducted to decipher the impression on the mind of the viewer, i.e. an attempt to 'understand his understanding 'of the

\author{
Dr. C.Lalmuansangkimi \\ Assistant Professor \\ IIMC NER Campus
}

subject. Thus, a combined analysis should evaluate the gaps and merits in the communication channel.

\section{RESEARCH OBJECTIVE}

The research is conducted to formulate a method to analyze internet memes and advertisements). The research serves as a tool for enthusiasts who like to determine "what the meaning of the media is' and how they're trying to communicate it. It is expected to increase the awareness and attention of signs embedded in internet memes and advertisements to the viewers. The study attempts to answer pertaining questions - What is the meaning of icon and symbol of each image under scrutiny? How participants interpret those images? What underlying quality of a meme makes it different from advertisements? to get the comprehension of evaluations of respondents.

\section{CRitical ApPRAisal of Related StUdies}

There are many researches available which use Semiotics and Audience reception to analyze advertisements and internet memes. Although, the present study is a first attempt to combine the two theoretical frameworks to analyze data. The research about advertisement that observed semiotics in State Islamic University Syarif Hidayatullah Jakarta has been done by Audia Erana (2015) with title "Pierce's Semiotics Analysis of Icon and Symbol on Perfume Advertisements". Audia used a sample of images of Perfume bottles of various brands to analyze them. The same approach has been incorporated to analyze internet memes and advertisements in the present study.

The research about audience reception for advertisements has been observed in a study by Figen and Yesim (2011) at Akdeniz University, Turkey titled "Television Advertisements: A Reception Study". The study attempts to answer how female and male participants interpret advertisements with symbolic expressions. The present study differs in a manner that it doesn't aim at segregating the interpretations based on gender but rather attempts to comprehend the philosophical logic behind the memes and advertisements. 


\section{RESEARCH METHOD}

A two-stage approach is employed in order to examine the communicative ability in the context of memes and advertisement. In the first stage, a thorough semiotic analysis is conducted on samples and recorded. The sample of content under scrutiny is selected based on popularity and diversity. In the second stage, written reactions of the participants/viewers are recorded and analyzed. An in-depth interview is conducted in order to reveal more detailed information. The audience reception is recorded at this stage and compared with the results in the first stage.

In order to examine how meaning is constructed, a sample of still image memes from the image macro category are selected for analysis. Image macros are essentially images with overlaid text, and they were selected for multiple reasons; they are the oldest, simplest and most wide-spread online meme category, and they are snackable images that are easy to share with a simple tweet or Facebook post (Owens, 2012).

\section{A. Sample}

A sample of image macros are selected based on their simplicity and popularity to access greater shared field of experience with the viewer. This is important to gauge viewer's experience vividly for an efficient communication in the second stage.

Snowball sampling is used to select the participants. Snowball sampling "yields a study sample through referrals made among people who share or know of others who possess some characteristics that are of research interest" (Biernacki \& Waldorf, 1981: 141).

\section{B. Reception Analysis}

The primary objective of reception studies, as a significant field in the qualitative research, is "to create, expand and refine theory by observing and interacting with people in their natural environment to discover rich explanations and unique instances" (Allen, Titsworth \& Hunt 2009: 4). There are a variety of studies examining the reception of advertisements in communication studies. In the tradition of reception research, the studies focus on reception investigate how different socialcultural groups interpret the texts. A number of studies have been conducted to analyze audiences ${ }^{\text {ce }}$ readings of advertisements in the literature. The present study exploits the same method to analyze audience reception to internet memes which also essentially consists of an image and text.

The combined analysis is conducted with a vision to establish a theoretical framework. The undertaken research method tends to a theory of exploiting a combination of two frameworks with a purpose to evaluate the communication channel between the source and viewer. The selected theoretical frameworks complement each other in a manner that the communication gap is bridged between the source (image, semiotic analysis) and the receiver (participant, reception analysis) while constructing it from either ends to meet at a point.
It is assumed that the proposed framework can defragment a communication thread to make it available for close analysis, i.e. byte by byte. These observations are recorded and interpreted. The outcomes are finally articulated in the research findings.

\section{Semiotic analysis}

Semiotics is the study of meaning-making, the study of sign process (semiosis) and meaningful communication. This includes the study of signs and sign processes, indication, designation,likeness, analogy, allegory, metonymy, metaphor, symbolism, signification, and communication.

Semiotics is frequently seen as having important anthropological dimensions; for example, the Italian semiotician and novelist Umberto Eco proposed that every cultural phenomenon may be studied as communication. Hence, semiotic analysis becomes indispensable to interpret internet memes as they impose relevance to cultural phenomena across peer groups. There are a plenty of studies that examine the creation of meaning through images and advertisements that exploit Semiotic framework for analysis. Ferdinand de Saussure, Roland Barthes, Charles Pierce Sanders, Umberto Eco are among the pioneers in the field of linguistics who laid the foundation of semiotics. Umberto Eco said that, Aristotle was also familiar with this concept of signification. Modern semiotics analysis is said to be popularized by two figures, Ferdinand de Saussure, a linguistic expert from Switzerland (1858-1913) and Charles Sanders Pierce, an American philosopher (1839-1914). Saussure divided a sign into two elements: signifier (soundimage) and signified (concept). While Pierce focused on three elements of signs, which are iconic dimension, indexes and symbols.

Stuart Hall said that, semiotics provides a method to analyze how visual representations deliver its meanings. In the works of Roland Barthes in 1960, linguistic models of Saussure were improved/extended through its application on areas of signs and a variety of broad representations (advertising, photography, popular culture, travel, fashion, etc.)

Pierce's works prove vital for the semiotic analysis because it conceives of and discusses things like representations, interpretations, and assertions broadly and in terms of philosophical logic, rather than in terms of psychology, linguistics, or social studies. As philosophical logic, it is about the drawing of conclusions deductive, inductive, or hypothetically explanatory. Peirce adopted the term semiosis and defined it to mean an "action, or influence, which is, or involves, a cooperation of three subjects, such as a sign, its object, and its interpretant, this tri-relative influence not being in any way resolvable into actions between pairs".

Peirce's definition of the triadic sign relation that formed the core of his definition of logic.

"A sign is something, $A$, which brings something, $B$, its interpretant sign determined or created by it, into the same 


\section{International Journal of Engineering Applied Sciences and Technology, 2019 \\ Vol. 4, Issue 5, ISSN No. 2455-2143, Pages 243-251 \\ Published Online September 2019 in IJEAST (http://www.ijeast.com)}

sort of correspondence with something, $C$, its object, as that in which itself stands to $C$." (Pierce,1902)

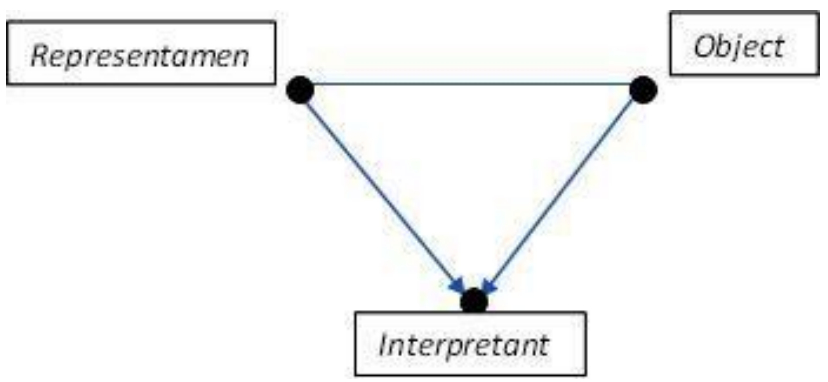

Fig. 1 Pierce's diagram of Semiosis

In Peirce's theory of signs, a sign is something that stands in a well-defined kind of relation to two other things, its object and its interpretant sign.

Peirce held that there are exactly three basic semiotic elements, the sign, object, and interpretant, as outlined above and fleshed out here in a bit more detail:

- A sign (or representamen) represents, in the broadest possible sense of "represents". It is something interpretable as saying something about something. It is not necessarily symbolic, linguistic, or artificial.

- An object (or semiotic object) is a subject matter of a sign and an interpretant. It can be anything discussable or thinkable, a thing, event, relationship, quality, law, argument, etc., and can even be fictional. The object most accurately is the universe of discourse to which the partial or special object belongs.

- An interpretant (or interpretant sign) is the sign's more or less clarified meaning or ramification, a kind of form or idea of the difference which the sign's being true would make. (Peirce's sign theory concerns meaning in the broadest sense, including logical implication, not just the meanings of words as properly clarified by a dictionary.) The interpretant is a sign (a) of the object and (b) of the interpretant's "predecessor" (the interpreted sign) as being a sign of the same object. The interpretant is an interpretation in the sense of a product of an interpretive process or a content in which an interpretive relation culminates, though this product or content may itself be an act, a state of agitation, a conduct, etc. Such is what is summed up in saying that the sign stands for the object to the interpretant.

Furthermore, Pierce stated that there are three elements in the semiosis process:

"A Sign, or Representamen, is a First which stands in such a genuine triadic relation to a Second, called its Object, as to be capable of determining a Third, called its Interpretant, to assume the same triadic relation to its Object in which it stands itself to the same Object. The triadic relation is genuine, that is its three members are bound together by it in a way that does not consist in any complexus of dyadic relation. That it the reason the Interpretant, or Third, cannot stand in a mere dyadic relation to the Object, but must stand in a relation to it as the Representamen itself does. Nor can the triadic relation in which the Third stands be merely similar to that in which the First stands, for this would make the relation of the Third to the First a degenerate Secondness merely."

It means that the three sides of the triangle (Representamen, Object and Interpretant) is something which should always stay together; inseparable like a sheet of paper. They're inseparable because they themselves determine the functions of each other such that the semiosis can describe the sign clearly.

Nevertheless, a Sign cannot call as the Firstness, and so forth. Definitely, Firstness is the probability or something that does not refer to anything else. Secondness, is the actual fact, or the sensation of feeling that appears. Thirdness is the general role or law, or a tendency how the representamen will be predicted.

For example, imagine a case in which a young girl suddenly pops up from her seat to dance after she hears a particular song play on speakers. It can be seen that the abrupt motion of her is the Firstness which is only a physical action. But the sudden action of her can be treated as a Representamen. Next, the Secondness as the actual fact - the Object which is the song, and Thirdness or the Interpretant is the connection between them. It can be correctly predicted that the young girl has a special association with the song.

Pierce further classifies the three elements of semiosis process i.e. Representamen, Object and Interpretant. The Representamen can be divided into three: qualisign which is formed by the quality such as the concept of a color; sinsign formed by the physical shape of a thing. Sinsign is the actual event or thing. And legisign which is the law or rule of how the thing should appear like a typical whistle sound when watching a soccer match (the activity here is, lauding) in comparison to the whistle sound when hitting on a girl. Mostly, legisign is made by the human to organize social life. Pierce divides the Object in three categories: Icon, Symbol and Index. Icon has the resemblance with the fact of what it refers or a sign which denotes or embodies character of the Object, whether it is real or imaginary. Symbol represents the general ideas that operate only in a particular situation, area or culture. Index reflects upon the cause-effect relationship between the sign and the object. Index has three characteristics:

1. Index has no resemblance to their Object.

2. It refers to individual or single unit.

3. It directs the attention or startle to its Object. 


\section{International Journal of Engineering Applied Sciences and Technology, 2019 \\ Vol. 4, Issue 5, ISSN No. 2455-2143, Pages 243-251 \\ Published Online September 2019 in IJEAST (http://www.ijeast.com)}

The Interpretant is divided into three: rheme, dicent and argument. The rheme is the probability for interpretant such as a concept, the dicent is the fact of interpretant or the real description of a thing, and argument is the logical reasoning of the interpretant. The rheme is a qualitative possibility that the interpretant will be understood. The dicent is the actual existence and argument is a sign of law or convention.

\begin{tabular}{|c|c|c|c|}
\hline & Firstness & Secondness & Thirdness \\
\hline Representamen & Qualisign & Sinsign & Legisign \\
\hline Object & Icon & Index & Symbol \\
\hline Interpretant & Rheme & Dicent & Argument \\
\hline
\end{tabular}

Table 1 Pierce's thought of Semiotics

The process of interpreting a sign's meaning from representative, objects and interpretan that is called 'semiosis' happens really fast inside our mind. Because of what actually sensed is representative, often times representative is called a sign. It is interesting that Peirce saw the semiosis as a neverending continuous process (unlimited process). He thought that interpretans can be received by our mind and seen as a new sign, or a new representamen. Meaning, a red light that has been interpreted by human's cognition is extended into a new representamen, for instance it becomes a 'prohibition' sign that refer as 'sanctions for violators' which then creates an interpretant as a law/prohibition that must not be violated. Or broadly, the word 'red' - which is a primary color might evoke different words in the mind of a viewer emanating from immediate thoughts and mental picture after hearing the 'sound' of the word 'red', say,

\section{Danger \\ 2.Blood \\ 3. Valentines' Day}

Hence, interpretants become new representamen (semiosis) repeatedly in a never-ending process.

Eco quoted Peirce "A sign is something by knowing which we know something more", said that a sign (he called it texts) is an opera aperta (an open work). This means that every sign, which is a part of a culture to a particular society, is always open to experience an unlimited semiotical process. A sign can be understood and interpreted differently by everyone within different places and different time, or even within the same person in different times and places. We can conclude that signs as a cultural element; is open to a variety of interpretation. Whatever theories that we use every day, the meaning is no longer inherent to the sign, instead it is given by the society who believes it.

Furthermore, the limitation of the semiosis process depends on the individual autonomy (exegesising ability) or the supra-individual principles (the values and norms in a culture which regulate the human habit) of the person who does the semiosis. (Benny Hoed,2011).

\section{Advertisements}

Advertisement is a product of advertising. According to William Wells, there are six elements to advertising definition. He states that an advertising, which the sponsor is identified, is a paid form of communication in order to persuade or influence the audience or mass through mass media. Because of that, an advertising is a non-personal communication. He also states the types of advertising: brand advertising, retail or local advertising, political advertising, directory advertising, direct-response advertising, business to business advertising, institutional advertising, public service advertising and interactive advertising.

Furthermore, Belch stated that advertising is used to create an image and symbolic appeals in differentiating one product from the others. It implies that an advertisement is an attempt to make a certain product stand out and bring its unique quality in the notice of the consumer, so to influence and interest them.

\section{E. Internet Meme}

Internet meme is empirically a message carrying commodity that emerged over internet and is circulated over it. It generally contains an image with an overlaid text that's supposed to convey a pop-cultural, political or a miscellaneous message. In recent years, it has become a very popular mode of communication among peer groups. Used for humor, therapy, gratification and protests, memes have served the internet generation well for they are free, instantly obvious and loaded with cathartic qualities (Ejaz, 2016).

The meme concept is an academic concept coined in 1976 by the biologist Richard Dawkins in his book The Selfish Gene. He proposed the term meme as a Darwinian, genecentered approach to cultural evolution, defining it as "the unit of 8cultural transmission". Nevertheless, nowadays it is possible to find the concept of meme almost everywhere on the internet, not making allusion to the concept created by Dawkins, but relating to certain kinds of images, jokes or trends popular within the internet users. Since 1976, the term meme has evolved, changed not only by different authors and theorists that follow or criticize Dawkins' theory, but also by its creator (Dawkins, 1993). The roots of the concept grew distant from its primal definition from a Darwinian perspective and began to grow in different ontological directions. This can be seen in the different uses theorists make of the term, e.g. by Blackmore (1999); Dawkins (1976, 1993).

"While the image is poetically powerful and, in all appearance, dramatically fits some on-functional (ill-adaptive) aspects of cultural life, the hypothesis still lacks basic elements for being taken seriously by the disciplines most obviously concerned such as the neurosciences, information theory, and sociology. The memetic hypothesis is indeed formulated as a loose analogy with genetics."- Paul Bouissac 


\section{International Journal of Engineering Applied Sciences and Technology, 2019 \\ Vol. 4, Issue 5, ISSN No. 2455-2143, Pages 243-251 \\ Published Online September 2019 in IJEAST (http://www.ijeast.com)}

The central feature of memes is what art philosopher Walter Benjamin would have called a Quotable Expression. Just like a piece of text can be quoted and used in different settings, an expression used in memes is quoted by way of screengrab, painting, photography or digital artwork. In memes, metaphor goes from the realm of language to the realm of image.

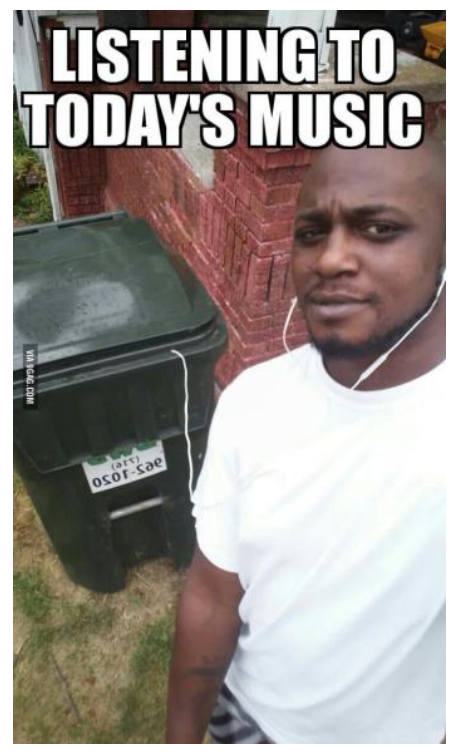

Fig.2

Consider the meme about the quality of modern music. To say that modern music is trash is a cliché. To say it in film and print would mean using the word "trash", but in meme a person can literally plug into a trash box and turn a redundant expression into a striking statement evoking laughter and realization of the state of music today. (Ejaz, 2016)

Over years, motion pictures and advertisements have been studied extensively while relatively new phenomena, but hugely popular: Internet meme has not received the deserved attention, while relevant research studies suggest that internet memes have been effective in influencing political discourse, public opinion and brand image of products and public figures widely over social media. The meagre ubiquity of memes over internet and its vast influence on the internet users makes it amenable for a study.

\section{EXPERIMENT AND RESULT}

The first-stage research employs descriptive analysis to analyze data by giving semiosis process then describing each datum to reveal the meaning. The semiosis is based on Pierce's theory of semiotics which emphasizes the second trichotomy of sign concerning of the relationship between representamen and its object. The second trichotomy based on Pierce are icon, symbol and index. In this research, it is only icon and symbol which will be analyzed. The icon itself is the photo or image and the symbol is overlaid text. Index is not analyzed because it relates to causality effect which is remotely relevant and does not fulfill the purpose of this research. Furthermore, the limitation of the semiosis process depends on the individual autonomy (exegesising ability) or the supra-individual principles (the values and norms in a culture which regulate the human habit) of the person who does the semiosis. (Benny Hoed,2011).

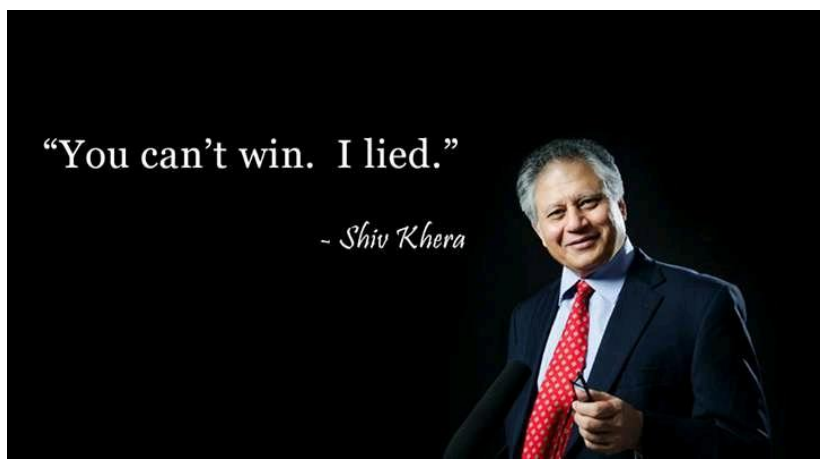

Fig. 3 Meme \#1

The above image (meme) Fig.3 has been taken from a Facebook page titled 'Mirror' owned by an anonymous author.In this image macro, the icon is the figure of a man and symbols are a quote and the name of the person to whom the quote belongs. The icon is the first that will be analyzed and then the symbol.

\begin{tabular}{|c|c|c|}
\hline Icon & A person & -empty- \\
\hline Symbol & A quote & Person's name \\
\hline \multicolumn{3}{|c}{ Table 2}
\end{tabular}

In this datum, there's a picture of a man (supposedly in late 50s) who bears an affectionate expression. This is the representamen $[\mathrm{R}]$. The man is dressed like a typical corporate fellow. But rather than displaying aggression, zealousness or ambitiousness; his attitude reflects calmness, composure, experience, self-certainty and a fatherly warmth. This is the object [O]. He holds his spectacles in his hand which is directed towards the viewer in way that he's extending an advice. Because of the relationship between the representamen and object, the interpretant is:

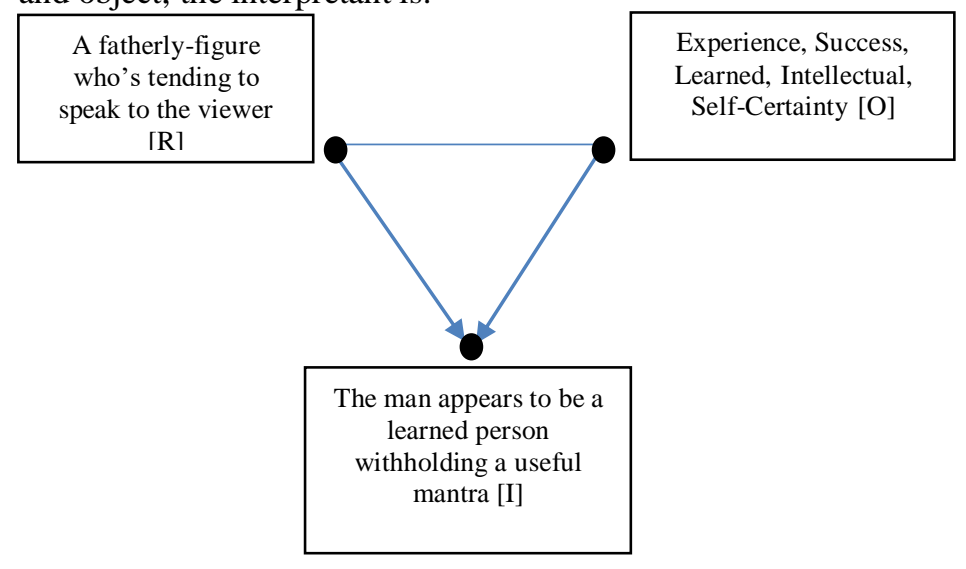

Fig. 4 


\section{International Journal of Engineering Applied Sciences and Technology, 2019 \\ Vol. 4, Issue 5, ISSN No. 2455-2143, Pages 243-251 \\ Published Online September 2019 in IJEAST (http://www.ijeast.com)}

Symbol, is the overlaid text on the image. There are two symbols in this image. First, 'Shiv Khera' - a renowned brand name, is the representamen [R] of the category legisign which denotes success guru, positivity, happiness[O] because it is popularly associated with that object among the youth of India. The relationship between the representamen and object produces interpretant in a semiosis process as follows:

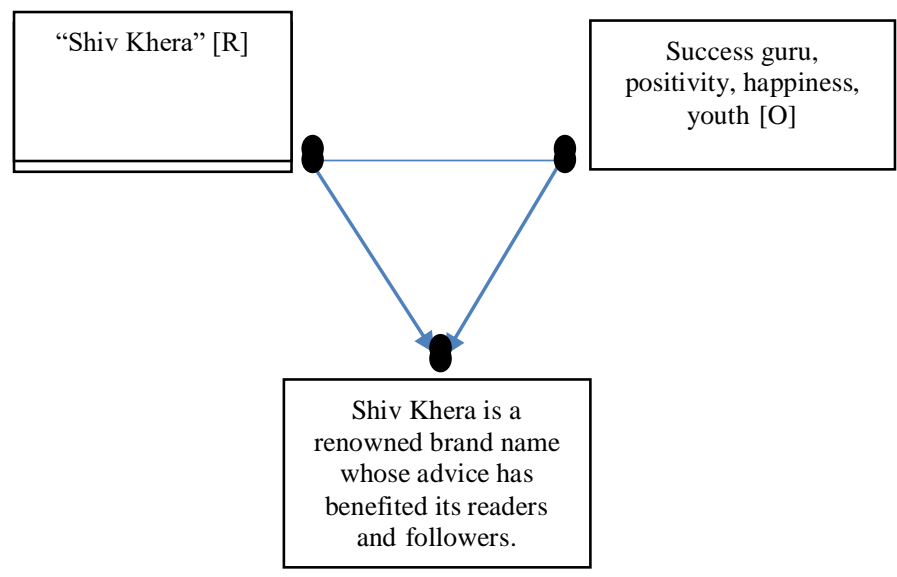

Fig. 5

The next symbol is a quote, "You can't win. I lied" which is in fact a misquote. The original popular quote is, "You can win" which is seen on the cover of one of his bestselling books titled "You can win."

The symbol becomes a representamen [R] because it is NOT an actual direct message to be consumed, but rather, it represents something. In fact, by making a complete 'antiquote', i.e. sharp contrast from the real quote that held a certain meaning, it now denotes a different meaning altogether. This symbol is not only in contrast with the original quote but also, the icon and its interpretant. The symbol destroys the previous object, i.e. credibility built by the icon (person)and previous symbol (brand name) in the image with a sense of derision that remarks the icon as deceitful, dummy, bogus, preposterous and a sell-out figure [O].

As a result, by bringing in the element of sarcasm, the image evokes a laughter among the viewers.

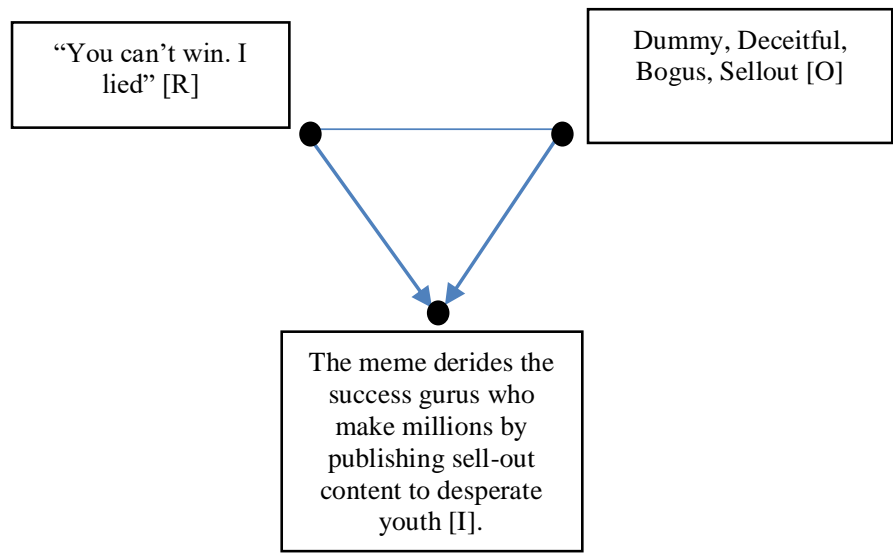

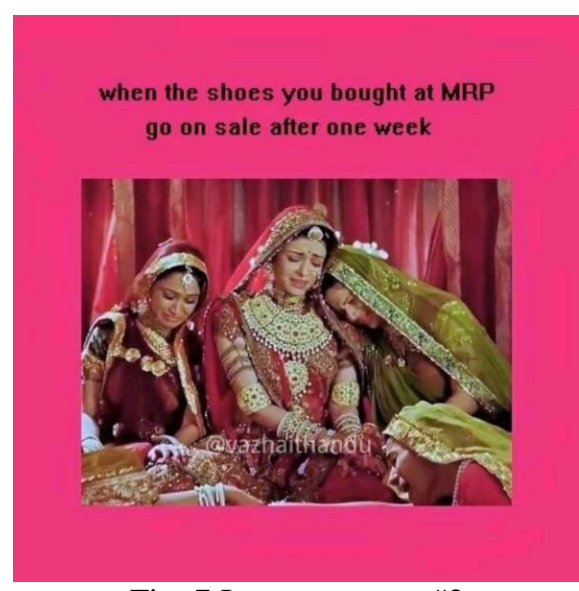

Fig. 7 Internet meme \#2

The above meme Fig.7 has been fetched from a Facebook page titled 'Behtar Memes' owned by Vazhaithandu.

\begin{tabular}{|l|l|}
\hline Icon & $\begin{array}{l}3 \text { women collectively } \\
\text { weeping }\end{array}$ \\
\hline Symbol & Text \\
\hline
\end{tabular}

In the above image, the icon is the image and the symbol the text. The icon will be analyzed first, followed by the text.

In the icon, a group of women $[\mathrm{R}]$ are seen sobbing[O]. Hence the relationship between $[\mathrm{R}]$ and $[\mathrm{O}]$ becomes:

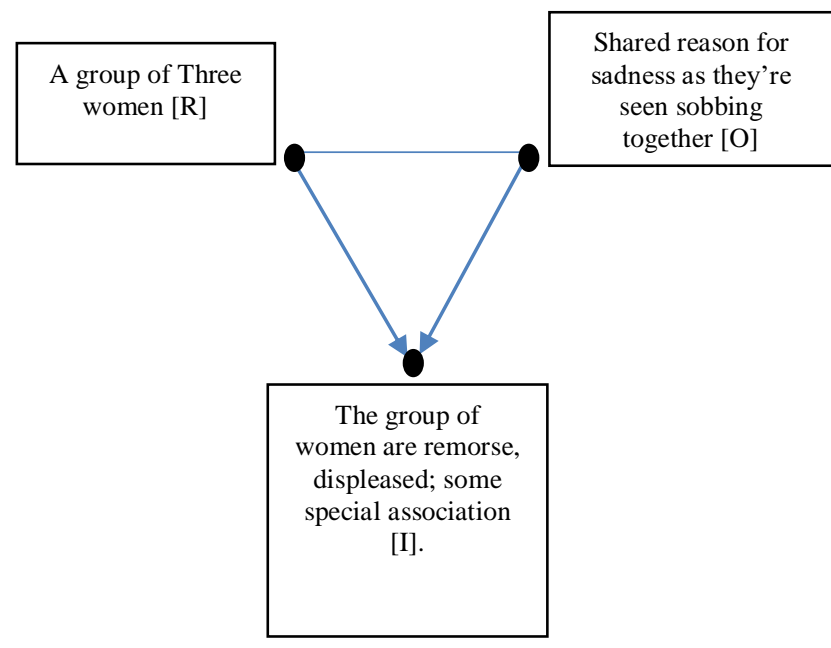

Fig.8

Next, is the symbol which is a text - "when the shoes you bought at MRP go on sale after one week" [R]. The text indicates loss of a golden opportunity. This forms the object [O]. The overlaid text quickly forms an association with the icon. The icon displays a setting where ladies who liked shopping (referring to shopaholics) are devastated upon learning that they missed out on a sale[I]. The meme thus, hyperinflates the stereotype by amplifying the reaction of the 


\section{International Journal of Engineering Applied Sciences and Technology, 2019 \\ Vol. 4, Issue 5, ISSN No. 2455-2143, Pages 243-251 \\ Published Online September 2019 in IJEAST (http://www.ijeast.com)}

women as a 'matter of serious concern' which apparently is not.

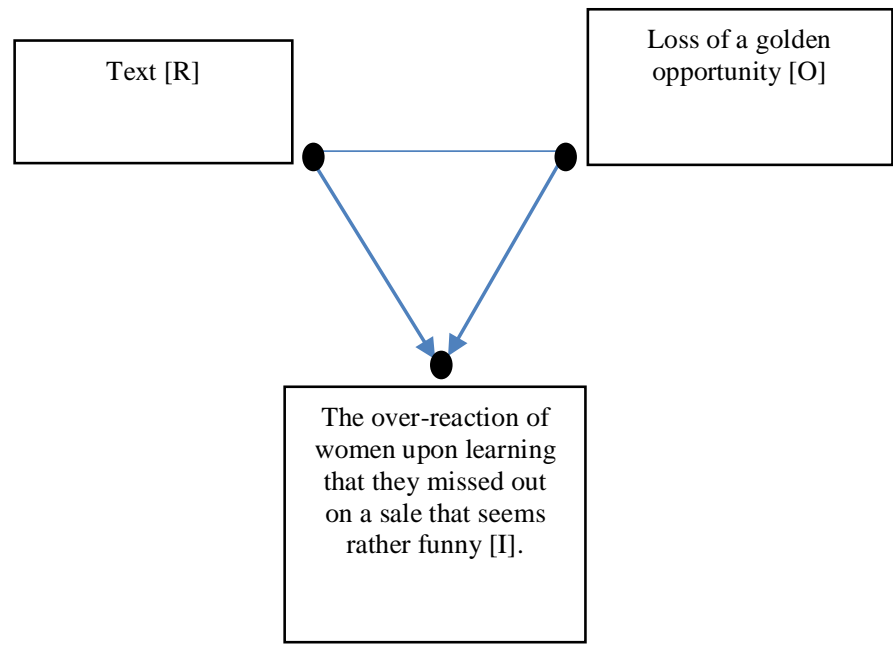

Fig. 9

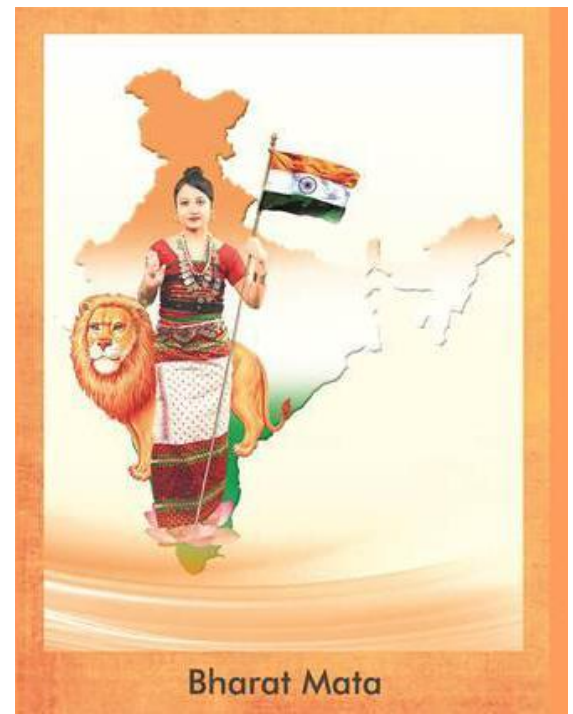

Fig. 10 \#Political Public Campaign/Advertisement

The above image Fig. 10 is a part of election campaign by Bhartiya Janata Party in the state elections of Tripura (2018) widely published across the state.

\begin{tabular}{|c|c|c|}
\hline Icon & $\begin{array}{c}\text { An image of a } \\
\text { young girl seated } \\
\text { on a lion in the } \\
\text { foreground of } \\
\text { Indian map }\end{array}$ & -empty- \\
\hline Symbol & $\begin{array}{c}\text { Text - "Bharat } \\
\text { Mata" }\end{array}$ & -empty- \\
\hline
\end{tabular}

Table 3

In this datum, the icon is the image of a young girl seated on a lion in the foreground of another picture of the Indian map. The symbol is the text, "Bharat Mata". The icons are analyzed first and then the symbol.

In the icon, a young girl [R] wearing traditional attires of the state's four major tribal communities is seated over a lion in the foreground of a map of Indian territory filled with a gradient of Indian tricolor. The depiction is a departure from the usual portrayal of Bharat Mata, a personified icon representing India. The replacement of the original Bharat Mata with a tribal girl creates an analogy with icon of Bharat Mata that signifies recognition of otherwise tribal community, empowerment and sense of inclusivity [O]. Because of the relationship between the representamen and object, the interpretant is:

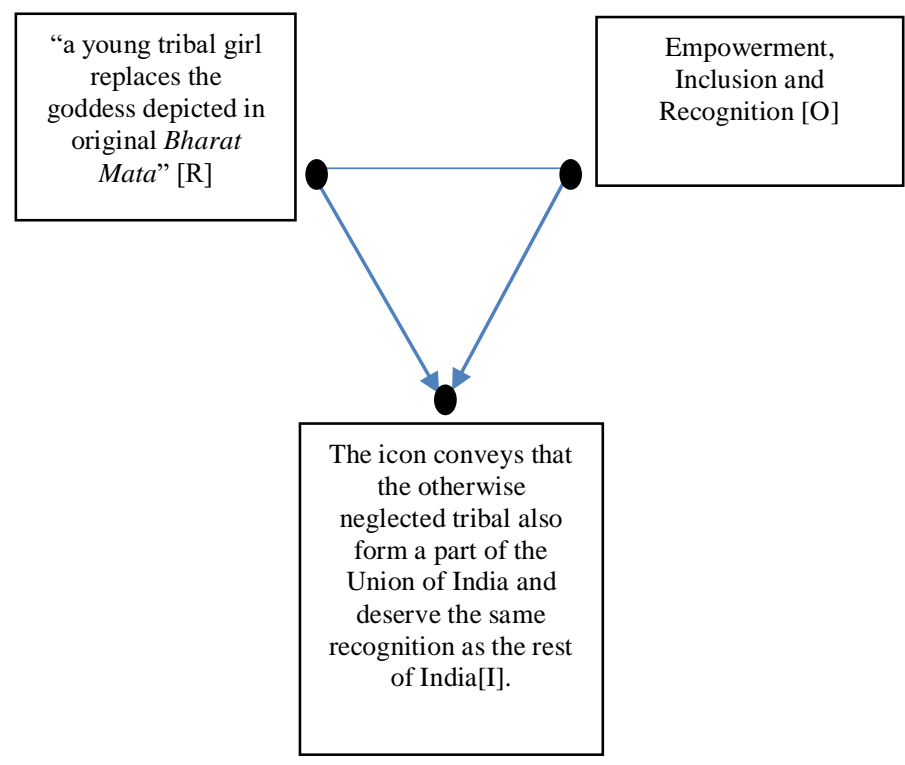

Fig.11

The symbol is a text, "Bharat Mata" which forms the representamen [R]. In connection with the icon, the symbol elevates an ordinary tribal girl to the status of a goddess that personifies the philosophy of India as a nation [O]. It reinforces the visual message and affirms the meaning to the interpretant. Pierce's model of the relationship between representamen and symbol becomes:

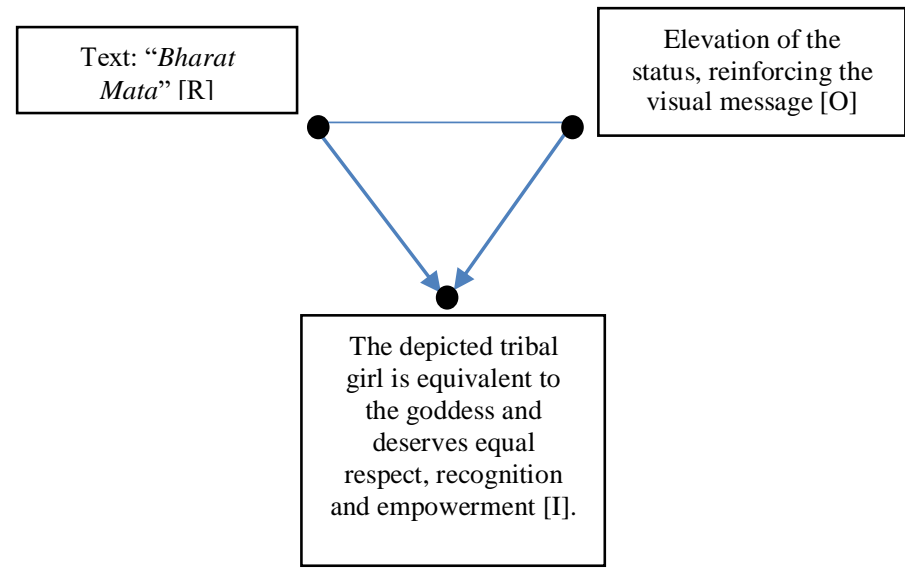




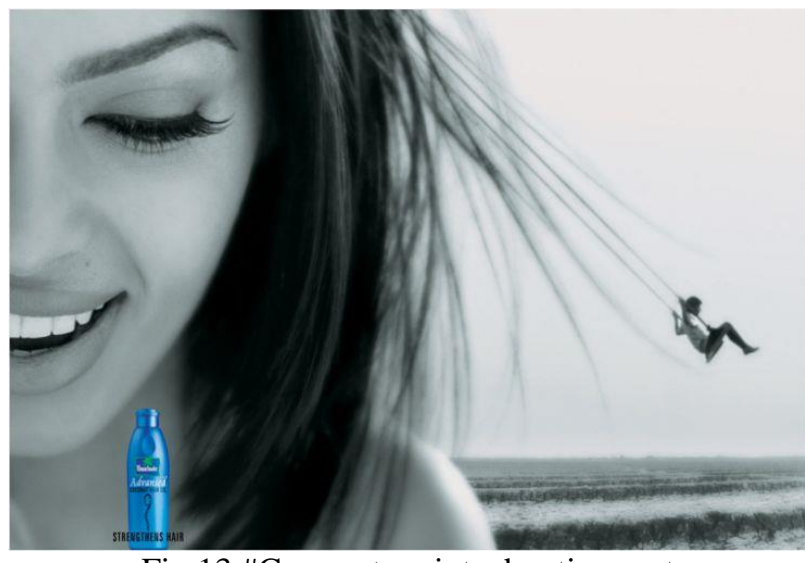

Fig.13 \#Corporate print advertisement

The Print Ad titled SWING Fig.13 was done by Ambience D'Arcy Mumbai advertising agency for product: Parachute Advanced Coconut Hair Oil (brand: Marico) in India. It was released in Aug 2002.

\begin{tabular}{|c|c|}
\hline Icon & $\begin{array}{c}\text { Background and } \\
\text { Product Image }\end{array}$ \\
\hline Symbol & Text - "Strengthens" \\
\hline
\end{tabular}

Table 4

In this datum, the background image shows a man swinging in full force whose strings are attached to the hair of a woman with the product image place in the foreground. This is the representamen $[R]$. The logical interpretation of the $[R]$ is that the hair is strong enough to hold a heavy weight without failure [O]. Thus, the relationship between the representamen and object is:

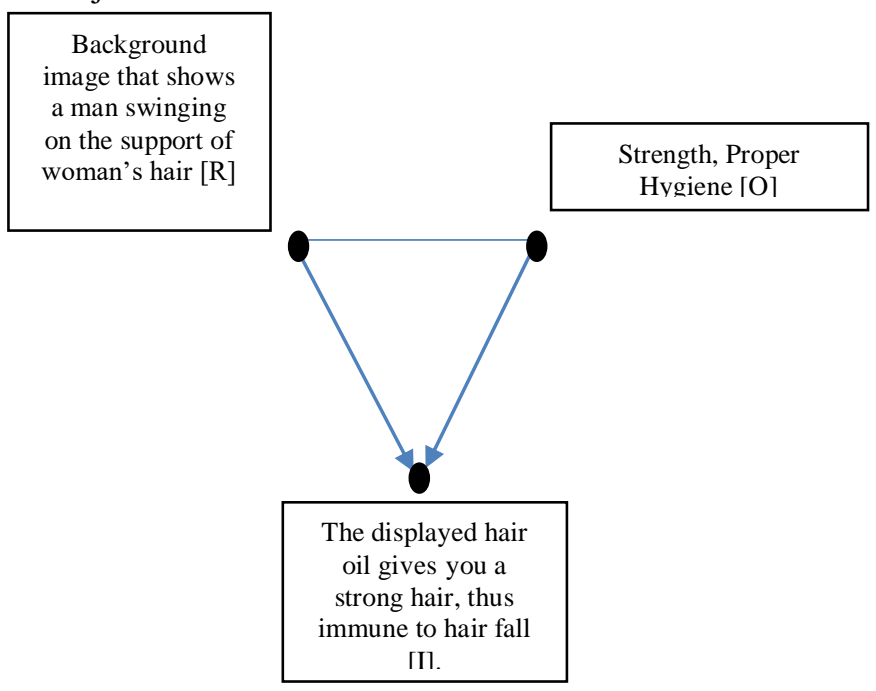

The symbol - a textual description of the quality of the product states, "Strengthens hair" is placed near the bottom of the product [R]. Thus, the quality of "strong hair" is ascribed to the specific product to which the advertisement belongs [O]. Pierce's model becomes:

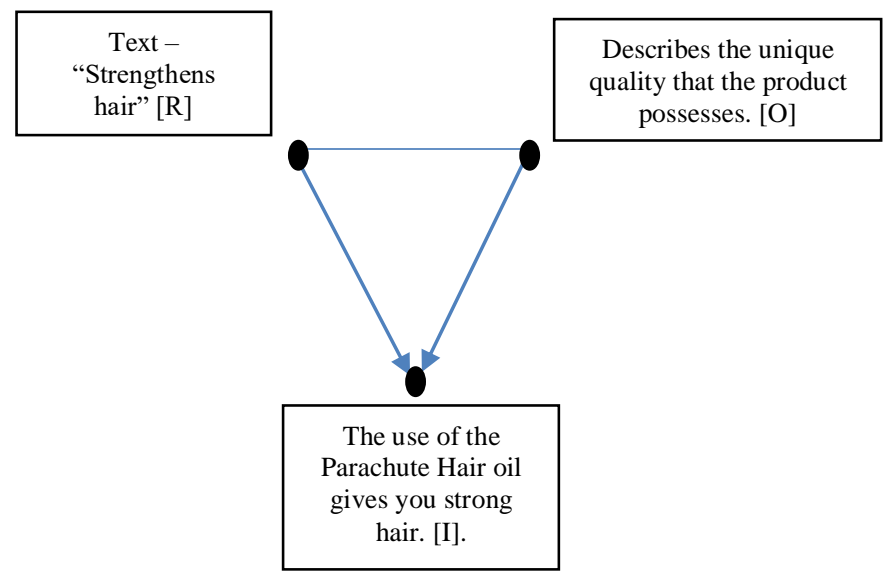

Fig. 15

A. Observation and Data insights

Meme \#1 and Print ad \#1 contain an element of sociocultural knowledge for the viewer to interpret and absorb the meaning it conveys. Thus, a shared field of reference must allow the viewer to engage deeply with the context of the media. A less familiarity with the background knowledge will cause hindrance in the correct interpretation of message and return respective reactions.

Meme \#2 and Print ad \#2 are a specimen of logical creativity that needs a thinking mind to interpret without prior knowledge of image elements. The meaning encompasses universal emotions that can be interpreted depending upon the exegesising capability of the viewer. A necessary shared field of reference is irrelevant in this case.

A mixed Qualitative- Quantitative method is applied to gather meaningful insights. In-depth interviews have helped to reveal greater information regarding the impression on the mind of the participant. All respondents are familiar with Internet memes. 56.5\% of respondents are fond of internet memes while $47.8 \%$ respondents look at advertisements. $52.2 \%$ respondents find memes cooler than other static visual media. While $52.2 \%$ respondents share memes, no respondents share advertisements. Only few respondents have a follow up thought after looking at meme \#1 and meme \#2. Similarly, only few respondents do not have a follow up thought after looking at print ad \#1. All respondents have an

Fig. 14 


\section{International Journal of Engineering Applied Sciences and Technology, 2019 \\ Vol. 4, Issue 5, ISSN No. 2455-2143, Pages 243-251 \\ Published Online September 2019 in IJEAST (http://www.ijeast.com)}

opinion on print ad \#1. $34.8 \%$ of respondents do not feel convinced by the print ad \#2, 26.1\% respondents are left unabridged by the advertisement. $21.6 \%$ of respondents guessed the print ad \#2 belonged to a product other than the correct after correctly describing the image elements. 30\% respondents find print ad \#2 over-exaggerated and lame, 13\% of respondents find the theme of the ad as pleasing. Only 4 respondents had no reaction to meme \#2. All respondents correctly describe the image elements in meme \#2 and confirm the acknowledgment of the message it conveyed. All respondents who are not familiar with the image elements in meme\#1 correctly ascribe to the feel as analyzed before. All respondents who are familiar or not familiar with the image elements succeed to form a meaning out of meme \#1. All the respondents succeed to form a meaning out of meme \#2 that contained unfamiliar elements but represented a universal emotion. Most respondents react with a quick laugh to meme \#1 and meme \#2

\section{CONCLUSION}

The merit of high percentage of sharing of memes lies in various aspects. They have a greater degree of 'relatability' as they encompass universal emotions and deliver them quickly. This makes them highly shareable and viral as the reaction is immediate and explosive. Memes bring the viewer only a step or two into the meaning and releases them. Memes are incisive and quickly exhaustible.

While advertisements indulge a viewer into thinking, ruminating on the thoughts that follow. The immediate logical interpretation is often lost. Creative advertisements with clinical logic-based interpretant might not find its way into influencing and convincing the viewer. Advertisements that exploit socio-cultural values and norms are more successful in maximizing their scope of influence.

The viewer might access and use socio-cultural values, norms and presets of preloaded notions to interpret the message which deviates from direct logical meaning. The semiosis process is too fast to hold thoughts at the immediate direct message and enter a never ending continuous process. This concurs with Charles' philosophy of semiosis who saw it as a never-ending continuous process (unlimited process).

Lack of familiarity and knowledge can hinder the communication process to a great extent as the viewer lacks the tools (assuming him/her a faculty of mind) to interpret the underlying message, i.e. only purported logical meaning cannot necessarily embark upon the viewer's impression. Hence, mind can exhibit confusion or face hindrance while interpreting the message.

\section{REFERENCE}

[1] Ebren, F., \& Celik, Y. (2011). Television Advertisements: A Reception Study from Turkey. Turkish Online Journal of Qualitative Inquiry, 2(3), 40-66.

[2] Eriana, A. (2015). Peirce's semiotics analysis of icon and symbol on perfume advertisements (Doctoral dissertation).

[3] Huntington, H. E. (2013). Subversive memes: Internet memes as a form of visual rhetoric. AoIR Selected Papers of Internet Research, 3.

[4] Nowak, J. (2016). Internet meme as meaningful discourse: Towards a theory of multiparticipant popular online content. Central European Journal of Communication, 9(16),73-89.

[5] Plevriti, V. (2014). Satirical user-generated memes as an effective source of political criticism, extending debate and enhancing civic engagement. Unpublished doctoral dissertation). The University of Warwick, Coventry, England.

[6] Rifa'i, B. (2010). A Semiotic analysis on coca-cola's commercial advertisements.

[7] Raftopoulou, C. (2007). Audience Reception of HealthPromoting Advertising: Young adult smokers makesense, interpret and decode shocking anti-smoking avertisements. Media@ LSE, Department of Meia and Communications.

[8] Sharma, P., \& Gupta, P. (2015). Semiotic analysis of Indian television advertisements and its impact on consumers: an exploratory study. ESSACHESS-Journal for Communication Studies, 8(1 (15)), 71-90. 